\title{
Modelling Calendar Time Structure for Open Pit Mining Equipment Performance Calculations
}

\author{
Ritter $\mathbf{R}^{1 *}$ and Stoyan $\mathbf{D}^{2}$ \\ ${ }^{1}$ Takraf Mining Technology Centre, Germany \\ ${ }^{2}$ Institut für Stochastik, TU Bergakademie Freiberg, Germany \\ *Corresponding author: Ritter R, Takraf Mining Technology Centre, Bahnhofstraße 26, 01979 Lauchhammer, Germany
}

Submission: 海July 5, 2018; Published: 眥October 10, 2018

\begin{abstract}
The effective operating time (EOT) of the equipment in an open pit mine determines the capacity of the mine. Clearly, EOT is only a part of the total calendar time, which also includes various down times or non-productive times, caused by different factors. Therefore, it is important to analyze the components of calendar time. A logical prerequisite for such an analysis as well as for predicting the capacity of a projected mine is a plausible model of calendar time structure and clear definitions of its components. We present here such a model, which is based on a comparative study of calendar time structure models used by several mining companies. Furthermore, we discuss the proportionality of downtimes and non-productive times to the EOT. This is fundamental for the prediction of the capacity of open-pit mines in projection, rationalization or expansion.
\end{abstract}

\section{Introduction}

Modeling the structure of the calendar time of industrial complexes is by no means a formal task. It is fundamental for performance measurement of an enterprise, for the rationalization of its operations, for the organization of the performance metrics, for benchmarking of various enterprises of the same company and for projecting new enterprises. It is particularly important for mining, because there are many different components of calendar time, especially various down-times associated to different reasons.

In the present paper, we consider open pit mines, as this case is important since the equipment of these mines is very expensive and can reach initial capital cost in the range of hundreds of million dollar for an entire system [1]. We consider structuring the calendar time of the machines in the sequence the material excavation process starts, i.e. shovels, loaders or excavators. (In the following we use for simplicity the general term 'loader'.) The main component of calendar time, effective operating time, $\mathrm{EOT}, \mathrm{t}_{\mathrm{E} 0^{\prime}}$ determines the annual capacity $\mathrm{C}$ of a loader, the total mass loaded during a year. Indeed, if $\mathrm{C}_{\mathrm{h}}$ is the hourly capacity of a loader, i.e. the mean mass load per hour, then

$$
C=C_{\mathrm{h}} t_{E O}
$$

It is a well-known and difficult problem to predict $\mathrm{C}_{\mathrm{h}}$ for new operational conditions [2-4], while it is easy to determine it for a loader in a given mine. If a mine has $\mathrm{n}$ loaders, the total annual capacity of the mine is $\mathrm{C}_{\text {mine }}$ given by

$$
C_{\text {mine }}=\sum_{i=1}^{n} C_{i}
$$

where $C_{i}$ is the annual capacity of loader $i$. The present paper discusses models of calendar time structure and the determination of $t_{\mathrm{E}}$. These are difficult problems since there are many complicated, imponderable influences on mining equipment: variable (perhaps unpredictable) geological conditions, variable break-downs of different nature and typically random processing times, e.g. loading, traveling and repair times. Therefore, the loaders cannot work all the time as desired, and there are many down-times, which are often random and difficult to predict.

Necessary conditions for a successful analysis of these times are a clear (and plausible) model of the structure of the calendar time and well-thought definitions of the various down-times and nonproductive times. It is important to separate down-times that are influenced by operators and that not, which are planned, and which are random and unpredictable. Furthermore, the understanding of the mining processes is important to know which of down-times are proportional to work-time and which not, which can be controlled by operators and which not. The planner should also know the cases where the prediction is easy and where difficult.

The present paper approaches the problem of structuring calendar time systematically for all types of open pit mining transport, with conveyors as well as with trucks. Starting from models used by multiple international mining companies, we come to a recommendation that combines the strengths of the existing or earlier used models. This also includes proposals for symbols of the structured components. Then we discuss the various types of proportionality of down-times and work-times and make some 
recommendations for the internal performance metrics. We show that there is only one component of calendar time that is seriously difficult to determine: the total annual waiting time of a loader in situations in which it could work however must be idle since no transport is possible, either since no trucks are available or the corresponding conveyor is not working.

\section{Calendar time structures}

Four established calendar time structures: We now present four calendar time structure models from the international mining industry. They are, in parts, differently organized and use different names for the time components. This shows that despite current efforts made by the Global Mining Standards and Guidelines Group $[5,6]$ the mining industry has not yet developed a common standard of deriving or stating equipment performance $[7,8]$. Most large mining companies have their internal "standard" nomenclature and time usage model. The following three figures show current examples of such models from three major mining companies. We explain them only briefly, expecting that the reader will understand the figures easily.

The Glencore time usage model: As one of the world leading commodity corporations, Glencore business areas comprise et alia of the production of bauxite, iron ore, nickel, zinc, copper, lead as well as coal. Most Glencore's mining operations use mobile equipment such as truck and shovel. The Glencore model is quite clear and simple and surely sufficient for the company. It contains very clear definitions of the various calendar time components. Nevertheless, it does not consider the reasons for delays and unplanned maintenance times in detail, see Figure 1.

\begin{tabular}{|c|c|c|c|c|c|c|c|c|c|c|}
\hline \multicolumn{11}{|c|}{ Calendar Time (CT) } \\
\hline \multicolumn{10}{|c|}{ Scheduled Time (ST) } & \multirow{5}{*}{$\begin{array}{l}\text { Unscheduled } \\
\text { Time (UT) }\end{array}$} \\
\hline \multicolumn{8}{|c|}{ Working Time (WT) } & \multicolumn{2}{|c|}{ External Idle Time (IT) } & \\
\hline \multicolumn{6}{|c|}{ Available Time (AT) } & \multicolumn{2}{|c|}{ Maintenance Time (MT) } & \multirow{3}{*}{$\begin{array}{l}\text { Other } \\
\text { External } \\
\text { Idle Time } \\
\text { (OE) }\end{array}$} & \multirow{3}{*}{$\begin{array}{l}\text { Weather } \\
\text { External } \\
\text { Idle Time } \\
\text { (WE) }\end{array}$} & \\
\hline \multicolumn{2}{|c|}{ Operating Time (OT) } & \multicolumn{4}{|c|}{ Operating Delay Time (OD) } & \multirow{2}{*}{$\begin{array}{l}\text { Unplanned } \\
\text { Maint. Time } \\
\text { (UM) }\end{array}$} & \multirow{2}{*}{$\begin{array}{l}\text { Planned } \\
\text { Maint. Time } \\
\text { (PM) }\end{array}$} & & & \\
\hline $\begin{array}{l}\text { Dynamic } \\
\text { Operating } \\
\text { Time (DT) }\end{array}$ & $\begin{array}{c}\text { Non- } \\
\text { dynamic } \\
\text { Operating } \\
\text { Time (NT) }\end{array}$ & $\begin{array}{c}\text { Process } \\
\text { Delay Time } \\
\text { (PD) }\end{array}$ & $\begin{array}{l}\text { Unplanned } \\
\text { Delay Time } \\
\text { (UD) }\end{array}$ & $\begin{array}{c}\text { Labour } \\
\text { Delay Time } \\
\text { (LD) }\end{array}$ & $\begin{array}{l}\text { Standby } \\
\text { Delay Time } \\
\text { (SD) }\end{array}$ & & & & & \\
\hline
\end{tabular}

Figure 1: The Glencore time usage model [9].

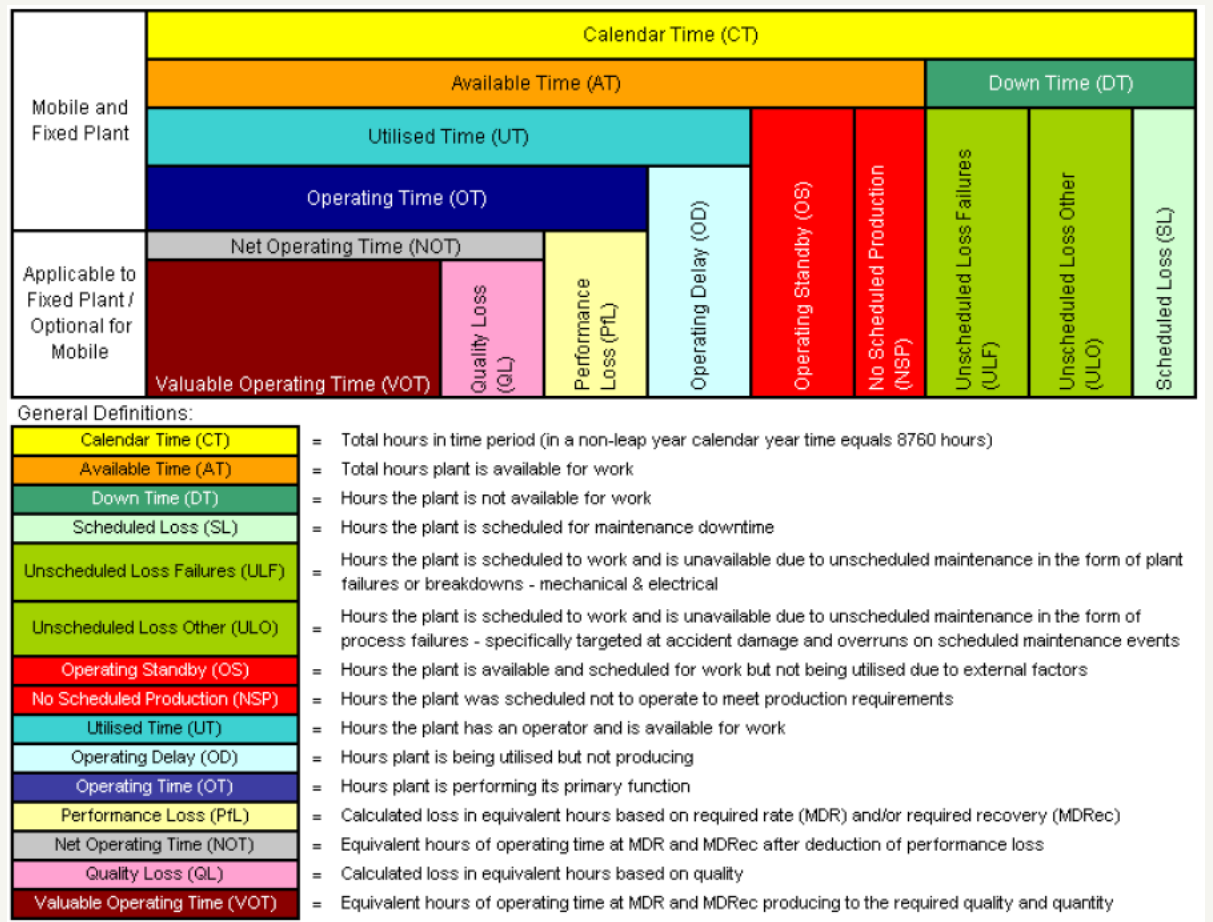

Figure 2: The Rio Tinto time usage model [10]

The Rio Tinto time usage model: The time usage model shown in Figure 2 from Rio Tinto was particularly made for its former coal operation of the company at Clermont (Australia), which now belongs to Glencore after the successful acquisition. This is a largescale open-cut operation, located approximately 12 kilometers from the town of Clermont in central Queensland. After commencing 
operations in 2010, Clermont now produces approximately 12 million metric tons of high-energy thermal coal with relatively low ash and sulphur using a truck and shovel method. The low run of mine strip ratio (3:2:1) and minimal processing (90\% coal does not need washing) combined with the high-quality coal, means the mine has a first quartile margin position in the seaborne thermal coal market. This calendar time structure model is still simpler than that of Glencore. It does not ask for the reasons of down times and so is of limited value for ways to improve the productivity of the mine.

The Western Premier Coal Limited time usage model: This calendar time structure model is similarly detailed as the Glencore model, see Figure 3.

\begin{tabular}{|c|c|c|c|c|c|c|c|c|}
\hline \multicolumn{9}{|c|}{ TOTAL TIME (CALENDAR) } \\
\hline \multicolumn{8}{|c|}{$\begin{array}{c}\text { ROSTERED (SCHEDULED) } \\
\text { (Total Time Equipment is Scheduled in Mine Plans }\end{array}$} & \multirow{4}{*}{$\begin{array}{c}\text { NON- } \\
\text { ROSTERED } \\
\text { (Time that } \\
\text { workforce is } \\
\text { not available } \\
\text { for work e.g. } \\
\text { public } \\
\text { holidays) }\end{array}$} \\
\hline \multicolumn{4}{|c|}{$\begin{array}{c}\text { AVAILABLE } \\
\text { (The accumulated time that equipment is operational) }\end{array}$} & \multicolumn{3}{|c|}{$\begin{array}{c}\text { MAINTENANCE DOWNTIME } \\
\text { (Non-available - The time that equipment is not in } \\
\text { operational condition) }\end{array}$} & \multirow{3}{*}{$\begin{array}{c}\text { LOST TIME } \\
\text { (Potential } \\
\text { operating time lost } \\
\text { due to } \\
\text { Environmental, } \\
\text { Fires, Flood, } \\
\text { Industrial Action) }\end{array}$} & \\
\hline $\begin{array}{r}\text { UTIL } \\
\text { (Time that equip } \\
\text { and } w\end{array}$ & $\begin{array}{l}\text { SED } \\
\text { nent is manned } \\
\text { rking) }\end{array}$ & $\begin{array}{r}\text { IL } \\
\text { (Time that } e \\
\text { operational } c \\
\text { wo }\end{array}$ & $\begin{array}{l}\text { LE } \\
\text { quipment is in } \\
\text { ondition but not } \\
\text { king) }\end{array}$ & $\begin{array}{r}\text { UNPL } \\
\text { (Time equipment } \\
\text { due to mec }\end{array}$ & $\begin{array}{l}\text { NNED } \\
\text { non-operational } \\
\text { anical fault) }\end{array}$ & $\begin{array}{l}\text { PLANNED } \\
\text { (Time equipment } \\
\text { is not available } \\
\text { due to }\end{array}$ & & \\
\hline $\begin{array}{c}\text { DIRECT } \\
\text { OPERATING } \\
\text { (Time when } \\
\text { production is } \\
\text { realised) }\end{array}$ & $\begin{array}{l}\text { INDIRECT } \\
\text { OPERATING } \\
\text { (Non-productive } \\
\text { time necessary } \\
\text { for production } \\
\text { operations) }\end{array}$ & $\begin{array}{l}\text { MANNED } \\
\text { (Time when } \\
\text { equipment and } \\
\text { operator are } \\
\text { idle) }\end{array}$ & $\begin{array}{l}\text { (Time when } \\
\text { equipment only is } \\
\text { idle) }\end{array}$ & $\begin{array}{l}\text { ACCIDENT } \\
\text { DAMAGE/ } \\
\text { OPPORTUNE } \\
\text { MAINT'NCE }\end{array}$ & BREAKDOWN & $\begin{array}{l}\text { maintenance } \\
\text { requirement) }\end{array}$ & & \\
\hline \multicolumn{2}{|c|}{$\begin{array}{l}\text { operations) } \\
\text { OPERATING }\end{array}$} & \multicolumn{7}{|c|}{ NON-OPERATING } \\
\hline \multicolumn{3}{|c|}{ MANNED } & \multirow{2}{*}{\multicolumn{5}{|c|}{ UNMANNED }} & \\
\hline \multicolumn{5}{|r|}{ NOTES } & & & & \\
\hline \multicolumn{2}{|c|}{ Rostered Time } & \multicolumn{3}{|c|}{ Total Hours accounted for in Planning Schedules. } & \multicolumn{4}{|c|}{ MAJOR PRODUCTION AND MAINTENANCE MEASURES } \\
\hline \multicolumn{2}{|c|}{ Available Time } & \multicolumn{3}{|c|}{$\begin{array}{l}\text { Accumulated hours that equipment is available to work } \\
\text { within Rostered time. }\end{array}$} & \multicolumn{4}{|c|}{$\begin{array}{l}\text { AVAILABILITY } \\
\text { Available Hours = Rostered Hours- (Lost Time + Maintenance Downtime) } \\
\text { Availability \% = Available Hours / (Available Hours + Maintenance Downtime) }\end{array}$} \\
\hline \multicolumn{2}{|c|}{ Direct Operating Time } & \multicolumn{3}{|c|}{ Time necessary to fulfill normal production operations. } & \multicolumn{4}{|c|}{$\begin{array}{c}\text { Availability \% = Available Hours / (Available Hours + Maintenance Downtime) } \\
\text { UTILISATION OF AVAILABILITY } \\
\text { Utilized Hours = Available Hours - Idle } \\
\text { Utilisation of Available Hours \% = Utilised Hours / Available Hours }\end{array}$} \\
\hline \multicolumn{2}{|c|}{ Indirect operating time } & \multicolumn{3}{|c|}{$\begin{array}{l}\text { Includes controllable but unavoidable delays to } \\
\text { operations. }\end{array}$} & \multicolumn{4}{|c|}{$\begin{array}{c}\text { Utilisation of Avallable Hours } \%=\text { Utillsed Hours } / \text { Avallable Hours } \\
\text { UTILISED } \\
\text { Utilised Hours = Available Hours - Idle } \\
\text { Utilisation } \%=\text { Utilised Hours } / \text { (Rostered }- \text { Lost Time) }\end{array}$} \\
\hline \multicolumn{2}{|c|}{ Idle and Unplanned Maintenance } & \multicolumn{3}{|c|}{$\begin{array}{l}\text { Unproductive time - may be due to surplus equipment } \\
\text { (unmanned idle time and opportune maintenance) } \\
\text { Excess operator delays (shift change, crib). }\end{array}$} & \multicolumn{4}{|c|}{ Productivity $=$ Production (BCM or Tonnes) $/$ Utilized Hours } \\
\hline \multicolumn{2}{|c|}{ Planned Maintenance } & \multicolumn{3}{|c|}{$\begin{array}{l}\text { Organized downtime incorporated into Mine Planning } \\
\text { schedules (Should included routine servicing and } \\
\text { preventative maintenance). }\end{array}$} & & & & \\
\hline
\end{tabular}

Figure 3: The Western Premier Coal Limited time usage model [11].

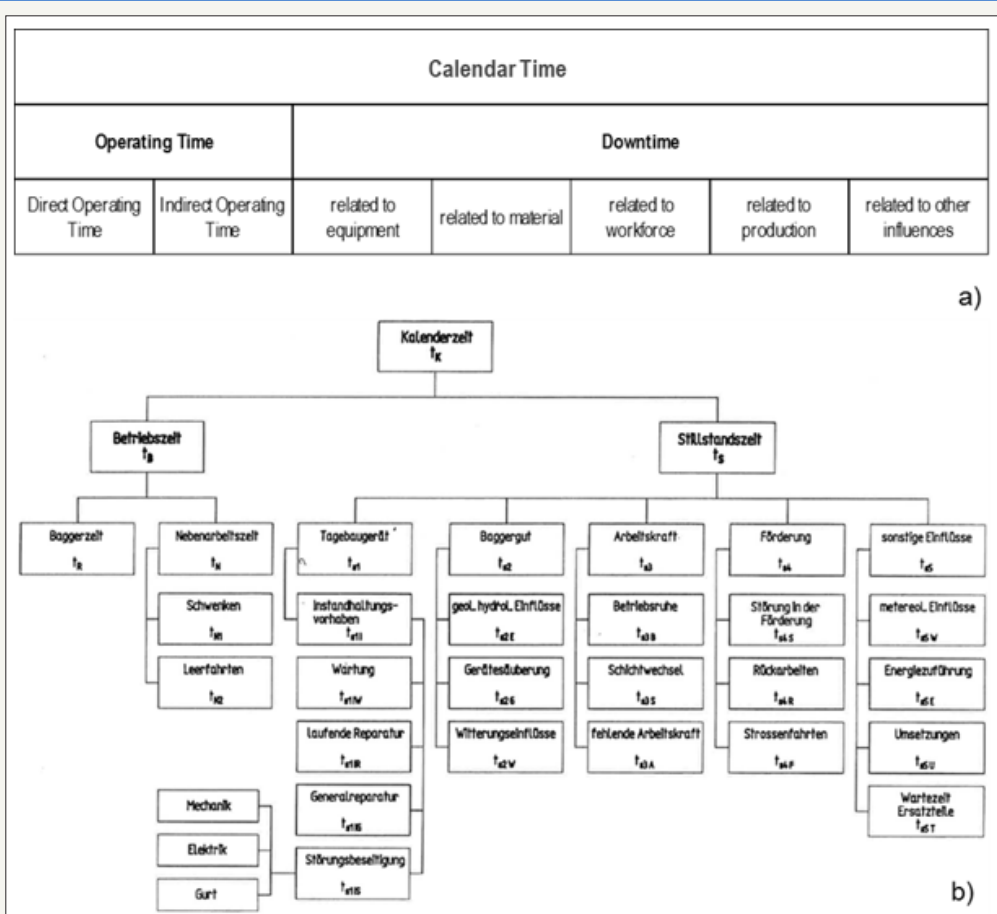

Figure 4: The TGL time usage model a) short version in English b) German [12].

The TGL time usage model: The TGL time usage model shown in Figure 4 was developed in East Germany before 1989 for its lignite open-pit mining. In that time the annual production of lignite was 300 mills. tons plus 2.800 mill. $\mathrm{m}^{3}$ overburden. Three mining districts used to exist with own management and traditions. It took long discussions to come to clear and generally accepted definitions for the calendar time components. The discussions were organized in a special committee for some years. At the end, the definitions 
were standardized (TGL was the East German counterpart to DIN) and their use was a duty in all mines. They were used in operation statistics, in the statistics of the mining districts, for planning and projecting. They were also presented in university teaching at Bergakademie Freiberg. To give the reader an impression of the true form of the TGL model, we present here also the original German version. The TGL time usage model is rather fine. The aim is to study in detail the reasons for down-times to achieve a maximum of EOT or $t_{\mathrm{EO}}$ In this way, the overburden excavators attained an EOT value of more than $60 \%$ (approx. $5260 \mathrm{~h} / \mathrm{a}$ ) of calendar time and the lignite excavators around $45 \%$ (approx. $4000 \mathrm{~h} / \mathrm{a}$ ). It was crucial to find out the responsibility for down times. Note, for example, the idle part of indirect operating time. It includes the time when a loader can work but the material cannot be transported because there is no truck to be loaded or the corresponding conveyor cannot work.

Our proposal for a calendar time structure model: The authors studied and compared the four calendar time structure models to come to a better new model. The result is shown in Figure 5. The main idea behind is the TGL time usage model, but we tried to design it as close as possible to the other models, in particular to the Western Premier Coal Limited time usage model.

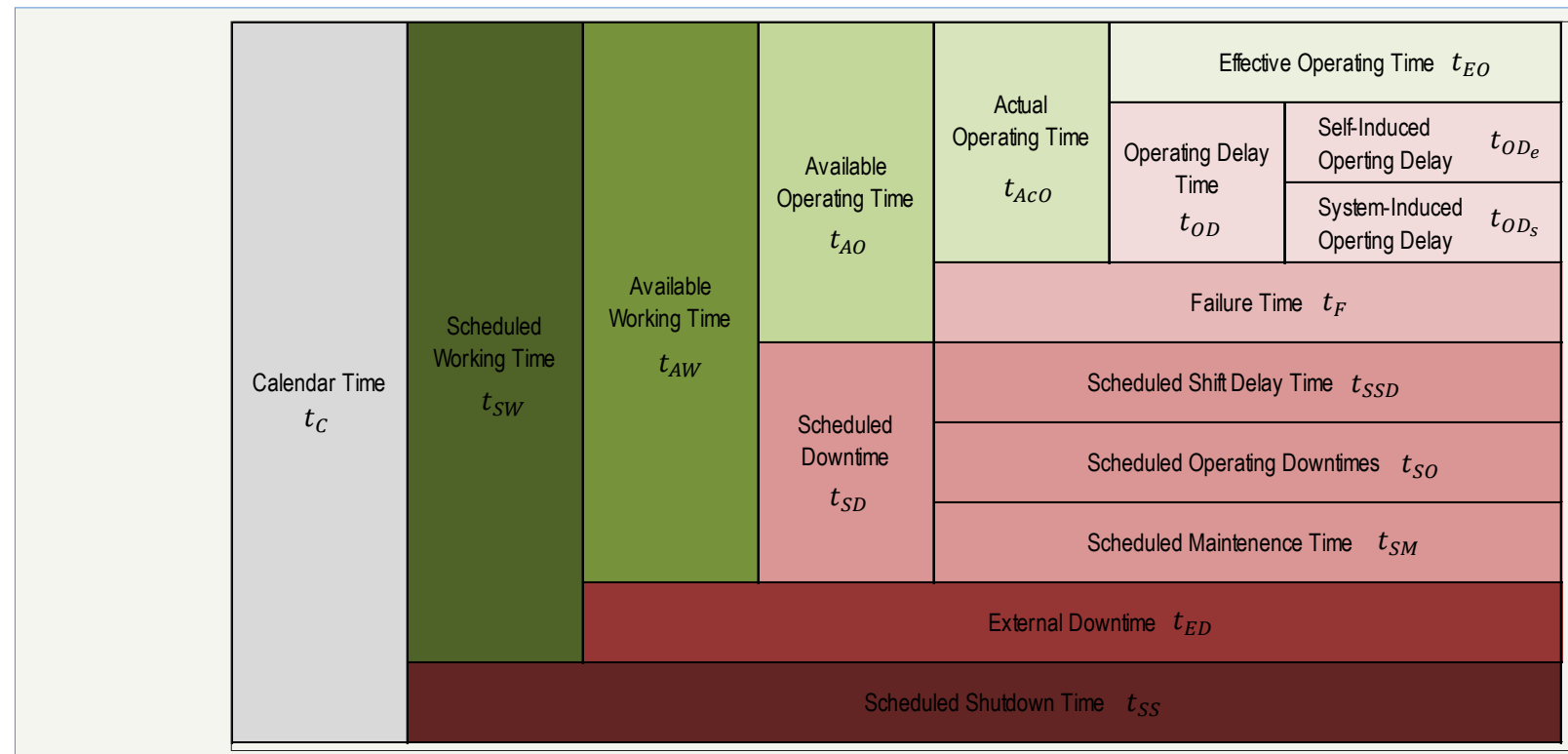

Figure 5: Proposed calendar time model. See the detailed explanation in the text.

Here we explain the components of the calendar time structure model.

A. Calendar time $t_{C}$ refers to all hours of every day around the year and is equal to 8.760 hours (ignoring leap years of 8.784 hours).

B. Scheduled shutdown $t_{\mathrm{sS}}$ includes all periods of time in which the loader is technically available but not scheduled to operate due to factors such as "non-worked holidays", "non-rostered work" (5-day per week operation, only day-shift operation, etc.), "training on equipment". In short, it represents the sum of all time components when the entire production process is not scheduled to operate.

C. Scheduled working time $\mathrm{t}_{\mathrm{sw}}$ includes all periods in which the loader is scheduled to operate, be supported, or maintained. The scheduled working time is generally a function of the roster (e.g. 5-day or 7-day roster with public holidays worked or not worked). Analysis against scheduled working time enables capacity to be examined based on the period when resources are normally allocated and accounts for differences in rosters. The scheduled working time is occasionally employed in the calculation of utilization (effective operating time/scheduled working time) to indicate performance of a process or equipment type when scheduled to operate. It holds

$$
t_{s w}=t_{c}-t_{s s}
$$

D. External downtime $t_{E D}$ includes all periods when the loader is scheduled to operate but cannot, due to "bad weather (wet weather, lightning, bad visibility et.)", "industrial disputes (strikes on-site or off-site)", "power outages", "governmental regulations (noise, dust, etc.)", i.e. time periods the management has no influence on.

E. Available work time $t_{A W}$ includes all periods when the loader is scheduled and capable of working unconstrained by external issues. Delays occurring during the available working time are directly related to the loader. The analysis of available work time enables performance of individual systems, equipment or processes to be compared within an operation or across a group of operations. It holds

$$
t_{A W}=t_{S W}-t_{E D}
$$

F. The available work time is divided into scheduled 
downtime $\mathrm{t}_{\mathrm{SD}}$ and available operating time $\mathrm{t}_{\mathrm{AO}}$.

G. Scheduled downtime $t_{\mathrm{SD}}$ consists of

I. Scheduled maintenance time $\mathrm{t}_{\mathrm{SM}}$, which includes all periods in which the loader is stopped according to a pre-defined plan (anything from life of asset to weekly schedule) to perform a routine inspection and/or service, maintenance task or change a component. In addition, corrective maintenance that is not immediately necessary and is deferred and planned for completion during or in conjunction with a scheduled service is recorded in scheduled maintenance time. We note that in case scheduled maintenance time for downstream equipment exceeds the one for the loader or cannot be conducted simultaneously it is required to add this time in this time component.

II. Scheduled operating downtimes $t_{\mathrm{so}}$, also referred to as process-related downtime, occur regularly and include times in which the loader is not operating due to required mine development or technological changes of the system. This includes "relocations of crusher or conveyor stations", "track shifting of conveyors", "conveyor belt extension or shortening", "blasting" etc.

III. Scheduled shift delays $\mathrm{t}_{\mathrm{SSD}}$ refer to periods that occur as regular shift events. These events include delays such as travel times to and from the pit, shift change, meal breaks, equipment inspections and safety meetings. They represent the sum of all shift delays in hours/shift multiplied by the available number of shifts per annum.

H. Available operating time $t_{A O}$ is the part of working time the loader is available for work and work-related activities. This includes the possibility of unexpected failures of the loader.

I. Failure time $t_{\mathrm{F}}$ includes all periods in which the work of the loader is stopped (randomly) by failures at itself. This includes all electrical, mechanical or communication failures directly attributed to the loader. Note that idle times caused by the transport system are not counted here; see below under "system-induced operating delays".

J. Actual operating time $t_{\text {Aco }}$ includes all periods in which the loader is functioning, which means the service meter is running (motor is running). Nevertheless, in a certain part of the actual operating time the loader is operating in an unproductive manner This is called "operating delay time". The time in which the loader is working at full effectiveness is referred to as "effective operating time".

$\mathrm{K}$. Operating delay time $\mathrm{t}_{\mathrm{OD}}$ includes all times the loader is scheduled, ready for work but does not work effectively. It is divided in self-induced operating delays and system-induced operating delays.

I. Self-induced operating delay time $t_{\text {ODe }}$ includes all periods in which the loader is performing its normal operating function but uses it for work necessary to ensure production, for example for pad preparation, face clean-ups and maneuvering.

II. System-induced operating delay time $t_{\mathrm{ODs}}$ includes all periods in which the loader is not able to operate and stands idle due to random interruptions of downstream equipment, by failure times of the related conveyor or by absence of trucks.

L. Effective operating time $t_{E O}$ is the union of all periods in which the loader is fulfilling its primary function.

The here presented time structure model of calendar time can be the starting point of an organization of performance metrics. The following section gives further relationships that help to use the structure model for projecting new enterprises or for estimating the effect of rationalizing of existing ones.

\section{Proportionalities}

For a precise prediction of $t_{\mathrm{E} o}$ it is useful to study the relationships of the various calendar time components. This will lead to the final equation (15) for $t_{E O}$ in the last section of this paper. Some of the calendar time components are fixed/known or can be easily determined. This holds true for the schedule shutdown time $t_{S S}$. The external downtime $t_{E D}$ can only be estimated using experience and empirical data. Finally, the components scheduled shift delay time $t_{S S D}$ and scheduled maintenance time $t_{S M}$ can be easily calculated considering the shift regime and the organization of maintenance. Other components can be determined because of the cyclic character of open-pit mining work, in which given blocks are mined. During each cycle, similar operations are carried out, which makes easy calculations possible.

Operation delay time: Operation delay time $t_{\text {ODe }}$ has two components in which the loader is in potential operating state but is not fulfilling its primary function, self-induced operating delay time $t_{\mathrm{ODe}}$ and system-induced operating delay time $t_{\mathrm{OD} \text { s }}$. The first component $\mathrm{t}_{\text {ODe }}$ includes all periods in which the loader is working but not for loading. For example, it prepares pads, cleans-up faces or maneuvers. These operations care carried out in every block. Clearly, the sum of all these times is proportional to the effective operating time $\mathrm{t}_{\mathrm{EO}}$ : If $\mathrm{t}_{\mathrm{EO}}$ increases, the number of blocks increases in direct proportionality. Therefore, it makes sense to write

$$
t_{\text {ODe }}=v t_{E 0}
$$

with a factor of proportionality $v$, which we call operating delay ratio. Its value can be determined by engineering reasoning, by analyzing the indirect operation work during a block cycle and determining the total amount of indirect operation work time in a cycle. The direct operation time per cycle can be determined from block volume and hourly capacity of the loader $\mathrm{C}_{\mathrm{h}}$. The ratio of these two times per block (indirect: direct) is equal to the operating delay ratio. In the thesis [13] there is an example for the determination of $v$.

The second component, $t_{\mathrm{ODs}}$, includes the times in which the loader could work but does not since no transport is possible. That means that either no empty truck is waiting at the loader to be loaded or the conveyor at the loader does not work (if there is direct connection loader-conveyor; or via a mobile crusher). These times depend on the behavior of the mining transport system. For an existing mine the determination of $\mathrm{t}_{\mathrm{ODs}}$ is not difficult, given a 
functional data acquisition system and cooperative loader personal. However, in the context of projecting and rationalizing it is a serious problem. For its solution, sophisticated mathematical methods have been employed.

For the case of conveyor transport, we refer to the classical paper [14] and the books [15,16]. Here analytical methods of mathematical reliability theory lead to results. Still more complicated is the case of truck transport. There methods of queuing theory have been used [17-19], which yield approximations, and discrete event simulations if precise solutions (e.g. for the case of rationalizing) are needed [20,21]. In both calculation methods, not all details of the work in the mine are considered. Usually, most of the down times are ignored and only the processes in the available operating time are simulated or modelled. These calculations must be organized in such a way that the ratio $t_{\mathrm{ODs}} / \mathrm{t}_{\mathrm{EO}}$ is determined. We denote it by $\zeta$ and call it system delay ratio,defined by

$$
\zeta=\frac{t_{O D s}}{t_{O E}}
$$

Failure time

Failures of the loader appear when it is working, i.e. during $t_{\mathrm{EO}}$ and $t_{\mathrm{ODe}}$. Therefore, it is natural to assume that the failure time is Table 1: Repair ratios of open-pit mining equipment [16].

\begin{tabular}{|c|c|c|c|c|c|}
\hline \multirow{2}{*}{ Equipment Type } & \multirow{2}{*}{ Sample Size } & \multicolumn{4}{|c|}{ Repair Ratio } \\
\hline & & Min & Mean & Max & CV \\
\hline \multicolumn{6}{|l|}{ Loader } \\
\hline Cable Shovel & 11 & 0.083 & 0.170 & 0.270 & 0.35 \\
\hline Hydraulic Excavator & 13 & 0.091 & 0.157 & 0.299 & 0.40 \\
\hline Trucks & 20 & 0.031 & 0.128 & 0.230 & 0.50 \\
\hline Crusher & 10 & 0.035 & 0.117 & 0.238 & 0.62 \\
\hline Spreader & 19 & 0.022 & 0.059 & 0.118 & 0.48 \\
\hline \multicolumn{6}{|l|}{ Conveyor } \\
\hline Shift Able & 29 & 0.004 & 0.019 & 0.043 & 0.77 \\
\hline Relocatable & 21 & 0.001 & 0.012 & 0.050 & 1.06 \\
\hline Fix & 26 & 0.000 & 0.007 & 0.035 & 1.41 \\
\hline
\end{tabular}

The differences in the repair ratios of conveyors are technically plausible: fixed conveyors can be much better aligned and operate in less heavy conditions compared to shift able conveyors. This implies more frequent disturbances and, perhaps, longer repair times. This again leads to larger values of $\kappa$. Comparison of the $\kappa$ in [16], a book of 1972 for East German lignite mining, to those in Table 1, shows that the former values for shovel excavators, despite of technical progress, tend to be smaller than the modern values for loaders. We explain this by the material moved: In East German and Polish lignite mining rather soft material like sands, clays and tills are mined while the values in Table 1 are partly obtained from mines where the predominant material includes blasted hard rock like sandstone, granite, basalt etc. We note here that is may be useful to refine the determination of repair ratios in the performance metrics statistics by considering also the different reasons for disturbance. One may classify times as mechanical, electrical and proportional to the actual operating time minus system-induced operating delay time. This idea goes back to Gladysz [14] in 1964. Therefore, we write

$$
t_{F}=\kappa\left(t_{E O}+t_{O D e}\right)
$$

The factor of proportionality $\kappa$ we call repair ratio [13]. (Czaplicki [15], p. 130, uses the term "repair rate" for $\kappa$. We consider this as not suitable since $\kappa$ is dimensionless, while a rate is a quantity proportional to $\mathrm{t}^{-1}$. And we note that $\kappa$ is not a probability!) For repair ratios of mining equipment there is statistical data available. And we recommend that the existing mining companies should organize their performance metrics in such a way that for the most important machines, in particular loaders, the repair ratios are determined statistically. Table 1 shows some values collected by the first author [13], based on data from 11 mining operations in five countries. We mention that already in the books $[16,22]$ values of $\kappa$ were given, which represent the state of the 1970ies in East German and Polish lignite mining. Repair ratios depend on equipment type, on its conditions of work and service life and quality. We provide $\kappa$ values not only for loaders but also for other machines, as they are needed in the calculations leading to the system delay ratio $\zeta$. geologically caused disturbances.

Finally, note the fundamental difference between $\kappa$ and $\zeta$. The repair ratio characterizes the disturbance and repair behavior of a single element of the equipment of a mine, of a loader, while the system delay ratio $\zeta$ depends on the behavior of the whole transport system. For instance, it can be reduced by employment of further trucks. Statistical values of $\zeta$ from an existing mine cannot be used for another mine even if the geological conditions are similar but the setup of the transport system differs in terms of number and type of system elements. However, as an indication for the reader the system delay ratio $\zeta$ should be in the range of 0.2 and 0.6 for well-managed mines. In [1] various analytical and simulation methods to derive $\zeta$ are provided. In contrast, empirical $\kappa$ values for some equipment machines, e.g. loaders, can be used for projecting and rationalizing. 
Scheduled operating downtime: The scheduled operating downtime contains components that are proportional to effective operating time and others that can be considered as independent of. We discuss here only the proportional part, which we denote for simplicity by the original symbol $t_{\mathrm{so}}$. Examples for such time components are times for blasting and conveyor trackshifts. (If the effective loader work time is long, the mining process is big and blasting and trackshifting happens frequently.) In addition, here it makes sense to introduce a factor of proportionality to obtain

$$
t_{S O}=\tau t_{O E}
$$

where $\tau$ may be called technological downtime ratio. It can be determined by engineering calculations, similarly as the operating delay ratio. In the thesis [9] such a calculation is presented for an example.

Coordination of calendar time components: We mention that not all calendar time components are fully disjoint. By clever organization some planned operations can be carried out in parallel during down times. Two examples are:

A. During track-shift times some preventive maintenance can be carried out,

B. During times when the loader cannot work $\mathrm{t}_{\mathrm{os}}$ preventive repairs or indirect operations can be made, if the expected duration of the idle time is announced by an active dispatcher.

We ignore these possibilities since they may lead to only small (negligible) changes in the calculated calendar time structure.

Predicting the effective operation time: Based on the calendar time structure model a prediction of the effective operation time $t_{\mathrm{EO}}$ of loaders is possible. For this purpose, the calendar time components $t_{S S D}, t_{S M}, t_{\mathrm{ED}}$ and $t_{S S}$ are estimated or determined. By engineering calculations, the ratios and $\tau$ are determined. Using statistical data or experience, analogically the repair ratio is determined, and finally the system delay ratio $\zeta$ is estimated, by numerical calculation for the case of conveyor transport using mathematical reliability theory $[15,16]$ or for truck transport using queueing theory [17-19] or, as ultima ratio, using discrete event simulation $[20,21]$.

The starting point is the equation

$t_{c}=t_{E O}+t_{O D e}+t_{O D s}+t_{F}+t_{S O}+t_{S S D}+t_{S M}+t_{E D}+t_{S S}$

Using the theory above we have

$$
\begin{aligned}
& t_{O D e}=v t_{E O} \\
& t_{O D s}=\zeta t_{E O} \\
& t_{F}=\kappa(1+v) t_{E O}
\end{aligned}
$$

where we used the definition of $\kappa$ and equation (7), and

$$
t_{S O}=\tau t_{E O}
$$

Inserting these equations into equation (9) yields

$$
t_{C}=t_{E O}+\mathrm{v} t_{E O}+\zeta t_{E O}+\kappa(1+v) t_{E O}+\tau t_{E O}+t_{S S D}+t_{S M}+t_{E D}+t_{S S}
$$

And we obtain for $t_{\mathrm{EO}}$ the result

$$
t_{E O}=\frac{t_{C}-t_{S S D}-t_{S M}-t_{E D}-t_{S S}}{1+v+\zeta+\kappa(1+v)+\tau}
$$

\section{Discussion}

In this paper, we present a novel approach to determine the annual capacity of mining systems based on a structured time usage model, which was developed based on comparison of four different time usage models. This new time usage model states all essential time components and structures the time components by their relation to each other. Furthermore, the factor "system delay ratio" is introduced, which accounts for the random behavior of system elements and their interactions with one another and enables accurate calculation of system-induced operating delays. We demonstrate that the annual system capacity can be predicted by good engineering judgment and the use of the provided empirical values for repair ratio as soon as the hourly loader capacity is estimated. By using the proposed time usage model and the associated time component definitions a comparison of the annual capacity and EOT between various mines can be made. For that, we propose to develop a comprehensive event catalog that clearly designates various operating events to a single time component to establish a consistent method for future use. We hope that our paper will lead to a discussion on a generally accepted calendar time structure model and perhaps to improved tools for the capacity estimation of projected mines.

\section{References}

1. Ritter R (2014) Reliability and capacity planning of fully mobile IPCC systems. In: Moore P (Ed.), International IPCC Conference 2014 International Mining, Johannesburg, South Africa.

2. Osanloo M, Hekmat A (2005) Prediction of shovel productivity in the Gol-e-Gohar iron mine. J Min Sci 41: 177-184

3. Singh SP, Narendrula R (2006) Factors affecting the productivity of loaders in surface mines, International Journal of Mining, Reclamation and Environment 20(1): 20-32.

4. Walenzyk J (2014) Application Engineer, Komatso Mining Germany $\mathrm{GmbH}$ (personal communication). Excavator productivity, Germany.

5. CIM (2012) CIM Mining Standards and Guidelines Committee.

6. Lukacs Z (2014) Standard definitions for the benchmarking of availability and utilization of equipment Retrieved from http://www. smartmines.com/benchmarking/equipbenchmarking.html

7. Knights PF, Oyanader P (2005) Best-in-class maintenance benchmarks in Chilean open pit mines. CIM Bull 98(1088): 93.

8. Morriss P (2008) Key production drivers in in-pit crushing and conveying (IPCC) studies. South African Inst Min Metall, p. 33.

9. Glencore (2014) XCN BD GDL 0027 - Time model -Nomenclature and Key Performance Indicators. Internal Glencore Report. Unpublished.

10.Dalryple M (2014) Time usage model Rio Tinto (personal communication). Rio Tinto 2008 STA01-04 Asset Management Metrics. Internal Rio Tinto report. Unpublished.

11. Hardy RJ (2007) Selection criteria for loading and hauling equipment - Open pit mining applications. Western Australian School of Mines, Kalgoorlie, Australia.

12. TGL 32-778701-15 (1983) Definition of terms for open-pit mining. Structuring the calendar time for open-pit mining (in German). 
13. Ritter R (2016) Contribution to the capacity determination of semimobile in-pit crushing and conveying systems. PhD Thesis, TU Bergakademie Freiberg, Germany.

14. Gladysz S (1964) Process of damages of opencast machinery systems (in Polish). Wegiel Brunatny 1: 62-74.

15. Czaplicki JM (2010) Mining equipment and systems. Theory and practice of exploitation and reliability. CRC Press, Bota Raton, USA

16. Stoyan D, Stoyan H (1972) Mathematical methods of operations research: conveyance, mining and transportation (in German). Deutscher Verlag für Grundstoffindustrie, Leipzig, Germany.

17. Carmichael D (1986) Shovel-truck queues: A reconciliation of theory and practice. Constr Manage Econom 42(2): 161-177.
18. Carmichael D (1987) Engineering queues in construction and mining Ellis Horwood, Chichester, UK.

19. Daduna H, Krenzler R, Ritter R, Stoyan D (2018) Heuristic approximation and computational algorithms for closed networks: A case study in open-pit mining. Performance Evaluation 119: 5-26.

20. Banks J, Carson J, Nelson B, Nicol D (2010) In: Discrete-event simulation ( $5^{\text {th }}$ edn), Upper Saddle River NJ, Prentice Hall, USA.

21. Robinson S (2004) Simulation: The practice of model development and use. J Wiley \& Sons, Chichester, UK.

22. Sajkiewicz J (1980) Theory of machinery systems (in Polish). Wroclaw Poland.
Creative Commons Attribution 4.0 International License

For possible submissions Click Here

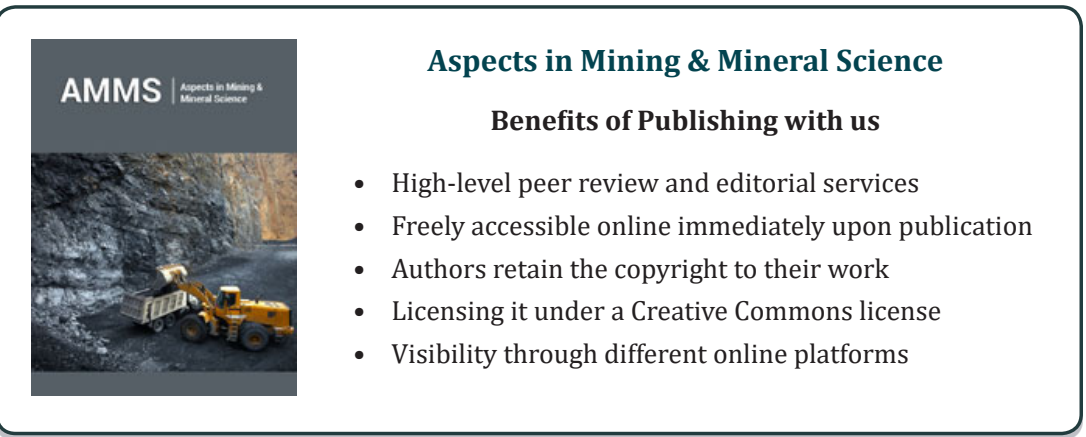

